\title{
Protocolo da extração de DNA de material parafinado para análise de microssatélites em leiomioma
}

\author{
DNA extraction from paraffin material protocol in order to analyse microssatellites in uterine leiomyoma
}

\author{
Ericson Martins Nascimento ${ }^{1}$ \\ Marilda Osti Spinelli ${ }^{1}$ \\ Consuelo Junqueira Rodrigues ${ }^{1}$ \\ Nilo Bozzini
}



The standardization of the protocol of the DNA extraction from paraffin material in order to analyze the instability of microsatellites in genes related to the uterine leiomyoma, using 30 to $40 \mathrm{mg}$ of tissue removed from paraffin blocks is presented. Desparaffin throught xilol baths to $65^{\circ} \mathrm{C}$, rehydrated with solutions of decreasing concentrations of ETOH and deionisation water. The extraction of DNA was obtained through

the stages of cellular lysis, with Promega solution, digestion of proteins by Proteinase $K$, precipitation proteins with Promega solution and precipitation of DNA with ETOH 70\% colded and ressuspended with Promega solution. This protocol results in a viable DNA to be use in the Polimerase Chain Reaction (PCR).

key words

Uterine leiomyoma

Instability of microsatellites

Paraffin material
O objetivo da presente comunicação é descrever um protocolo para extração de DNA genômico de tecido parafinado para análise em biologia molecular. $\mathrm{O}$ método consiste na desparafinização de $30 \mathrm{mg}$ a $40 \mathrm{mg}$ de tecido, seguida de reidratação e subseqüente extração do DNA, obtida através das etapas de lise celular, digestão enzimática de proteínas e precipitação do DNA. O emprego deste protocolo resulta em DNA de boa qualidade para amplificação pelo PCR.

A literatura descreve vários protocolos de extração de DNA para tecido a fresco, sangue e células em cul- tivo $(1,2)$. Tecidos embebidos em parafina também podem fornecer amostra de DNA, porém a sua extração necessita de um protocolo especial.

Com base nestes protocolos $(1,2)$, aplicamos os procedimentos para extração de DNA de fragmentos de leiomioma uterino, que haviam sido fixados em formalina não-tamponada e emblocados em parafina, com o objetivo de analisar marcadores de microssatélites. Por várias vezes obtivemos um DNA degradado e não-viável para amplificação pela reação em cadeia da polimerase (PCR). A presente comunicação 
tem por objetivo apresentar uma modificação do protocolo de extração de DNA, para tecido embebido em parafina, descrita por Wright e Manos (2).

O protocolo tem início com a obtenção das amostras a partir de blocos de parafina contendo fragmentos do tecido. Os blocos devem ser trimados para retirada do excesso de parafina e, depois, com auxílio de navalha histológica descartável, são obtidos $30 \mathrm{mg}$ a $40 \mathrm{mg}$ de material. Este material é transferido para um microtubo de $2.000 \mu \mathrm{l}$ e submetido, por duas vezes, a um banho de $1.000 \mu \mathrm{l}$ de xilol por 30 minutos a $65^{\circ} \mathrm{C}$, centrifugado a 14.000 rpm por 5 minutos, descartando-se o sobrenadante. Após a desparafinização deve-se retirar todo o xilol com um banho de $1.000 \mu \mathrm{l}$ de ETOH $100 \%$ e outro de $1.000 \mu \mathrm{l}$ de ETOH a 95\%, ambos à temperatura ambiente, por 1 minuto. Após esta etapa, o material deve ser reidratado com dois banhos de $1.000 \mu \mathrm{l}$ de ETOH a $70 \%$ e dois banhos de água deionizada. Em cada uma destas etapas o material deverá ser centrifugado a 14.000 rpm por $5 \mathrm{mi}$ nutos, sendo desprezado o sobrenadante. Estas etapas de lavagem do material são importantes para a retirada de todo xilol, pois este inativa a proteinase $\mathrm{K}$, utilizada na etapa seguinte para digestão das proteínas.

A partir do material hidratado inicia-se a digestão das proteínas e a extração propriamente dita do DNA. Para tal, devem-se adicionar $600 \mu$ l de solução de lise celular (Wizard Genomic DNA Purifications Kit - Promega) e incubar a $65^{\circ} \mathrm{C}$ por 60 minutos. A digestão das proteínas é feita adicionando-se solução de proteinase $K(10 \mu \mathrm{g} / \mu \mathrm{l})$, numa proporção de $3,5 u l$ da solução para cada $1 \mathrm{mg}$ de material parafinado, incubando-se overnight a $50^{\circ} \mathrm{C}-60^{\circ} \mathrm{C}$. Na próxima etapa devem-se adicionar $200 \mu$ l de solução de precipitação de proteínas (Wizard Genomic DNA Purifications Kit - Promega), homogeneizar, incubar 15 minutos em gelo, centrifugar a 14.000rpm por 2 minutos e descartar o sobrenadante. Neste recipiente acrescentamse $600 \mu \mathrm{l}$ de $\mathrm{ETOH}$ a $70 \%$ gelado, centrifuga-se a 14.000rpm por 2 minutos, despreza-se o sobrenadante e adicionam-se $30 \mu$ l de solução de reidratação de DNA (Wizard Genomic DNA Purifications Kit - Promega), incubando-se por 1 hora a $65^{\circ} \mathrm{C}$. Estas amostras devem ser armazenadas a $4^{\circ} \mathrm{C}$.

Com a utilização deste protocolo é possível se obter um DNA genômico de boa qualidade e concentração, verificada por análise em espectrofotometria, com razão A260/A280 = 1,7 a 2. A análise do DNA genômico total em gel de agarose a $2 \%$ (Figura 1 ) e de fragmentos de DNA amplificados por PCR (Figura 2) demonstrou que 0

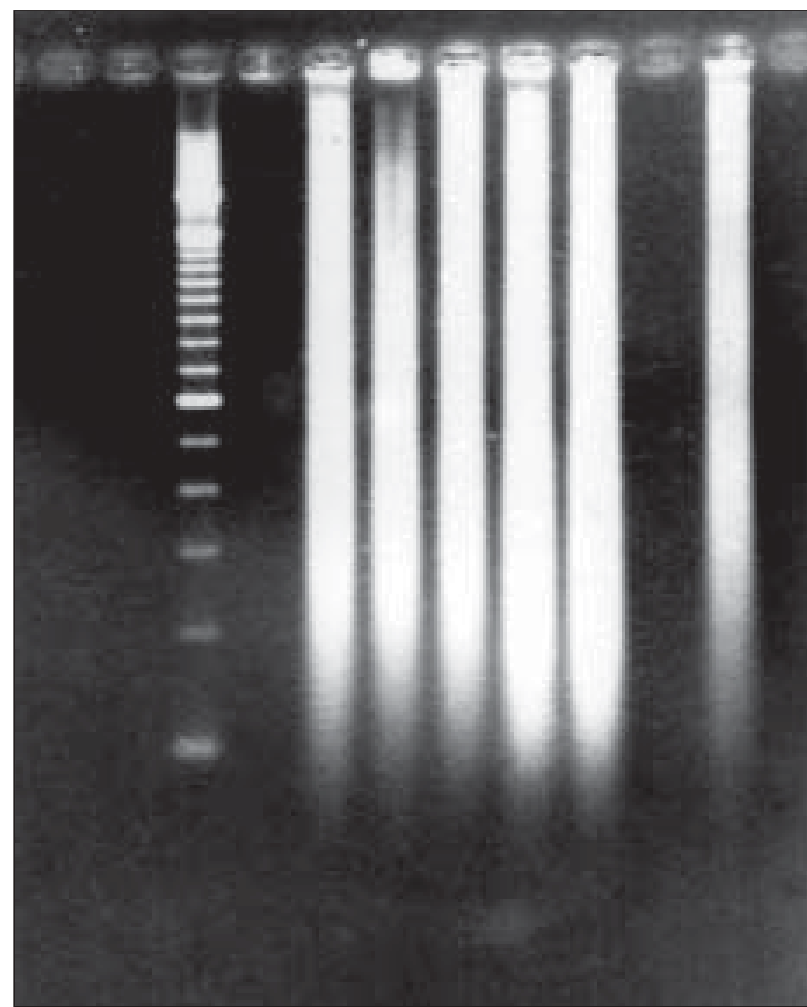

Figura 1 - Amostras de DNA total, extraídas de fragmentos de leiomiomas uterinos embebidos em parafina e submetidas a eletroforese em gel de agarose a $2 \%$

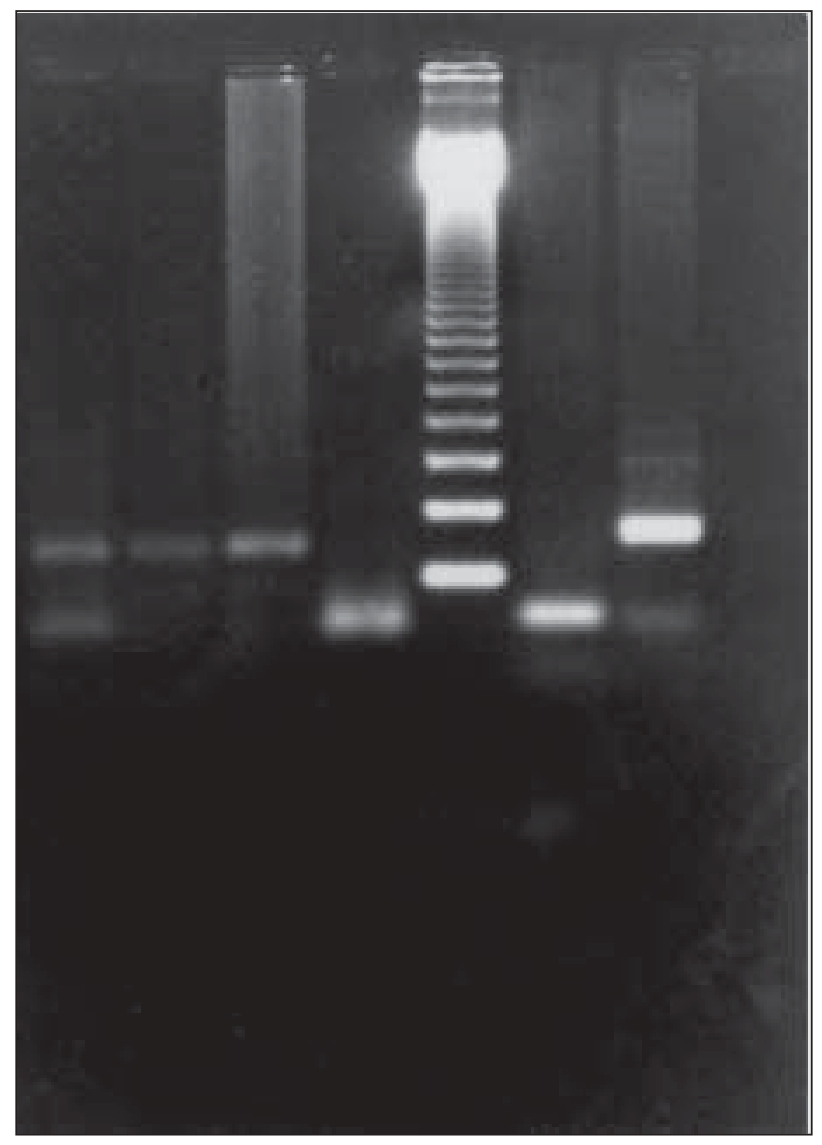

Figura 2 - Produto de PCR em gel de agarose. 1-3: Primer D75666; 4 e 6: Primer D7S501; 5: Ladder 123bp; 7: Primer D75471 
DNA extraído apresenta excelente viabilidade e sucesso na amplificação.

Outros kits de extração de DNA podem ser utilizados a partir de material desparafinizado, como os reagentes do GenomicPrep Cell and Tissue DNA Isolation Kit - Amershan
Pharmacia Biotech, lembrando que é necessário adicionar o volume adequado de proteinase $\mathrm{K}$ para digestão das proteínas. Técnicas in house e kits à base de magnetismo não demonstraram bons resultados para a extração de DNA de material parafinado.

\section{Referências}

1. Isola, J. et al.A nalysis of change in D N A sequence copy number by comparative genomic hybridization in archival paraffinembedded tumor sample. Am. J. Pathol.,145(6): 1301-8, 1994.
2.W right, D.K.\& Manos, M.M. Sample Preparation from Paraffin Embedded tissues. In: Innis, M.A. (ed.) PCR Protocols: a guide to methods and application. San Diego: Academic Press, 1990. p. 153-8. 